\section{REFERENCES}

1. Firth JB, Stuckey RE. Decomposition of trichloroethylene in closed circuit anesthesia. Lancet 1945;1:814-816.

2. Petty C. Carbon dioxide absorption. In: Petty C, ed. The Anesthesia Machine. New York, NY: Churchill Livingstone, Inc; 1987:67-79.

3. Middleton V, van Poznak A, Artusio JF Jr, Smith SM. Carbon monoxide accumulation in closed circuit anesthesia systems. Anesthesiology 1965;26:715-719.

4. Moon R, Ingram C, Brunner E, Meyer A. Spontaneous generation of carbon monoxide within anesthesia circuits. Anesthesiology 1991;75:A873. Abstract.

5. Fang ZX, Eger EI 2nd, Laster MJ, Chortkoff BS, Kandel L, Ionescu P. Carbon monoxide production from degradation of desflurane, enflurane, isoflurane, halothane, and sevoflurane by soda lime and Baralyme. Anesth Analg 1995;80:1187-1193.

6. Berry PD, Sessler DI, Larson MD. Severe carbon monoxide poisoning during desflurane anesthesia. Anesthesiology 1999;90:613-616.

7. Baxter PJ, Garton K, Kharasch ED. Mechanistic aspects of carbon monoxide formation from volatile anesthetics. Anesthesiology 1998;89:929-941.

8. Frink EJ Jr, Nogami WM, Morgan SE, Salmon RC. High carboxyhemoglobin concentrations occur in swine during desflurane anesthesia in the presence of partially dried carbon dioxide absorbents. Anesthesiology 1997;87:308-316.

9. Baxter PJ, Kharasch ED. Rehydration of desiccated Baralyme prevents carbon monoxide formation from desflurane in an anesthesia machine. Anesthesiology 1997;86:1061-1065.
10. Berry PD, Sessler DI, Larson MD. Severe carbon monoxide poisoning during desflurane anesthesia. Anesthesiology 1999;90:613-616.

11. Woehlck HJ, Dunning M 3rd, Connolly LA. Reduction in the incidence of carbon monoxide exposures in humans undergoing general anesthesia. Anesthesiology 1997:87:228-234.

12. Landry A. Carbon monoxide poisoning: sources, manifestations, treatment. Respiratory Therapy 1985;5:23-25.

13. Thom SR, Keim LW. Carbon monoxide poisoning: a review. Epidemiology, pathophysiology, clinical findings, and treatment options including hyperbaric oxygen therapy. J Toxicol Clin Toxicol 1989;27:141145.

14. Graves EJ. Kozak LJ. National hospital discharge survey: annual summary, 1996. Vital Health Stat 13. 1999 (140):i-iv, 1-46.

15. Barker SJ, Tremper KK. The effect of carbon monoxide inhalation on pulse oximetry and transcutaneous $\mathrm{pO}_{2}$. Anesthesiology 1987;66:667-669.

16. Vegfors $M$, Lennmarken $C$. Carboxyhaemoglobinaemia and pulse oximetry. BrJ Anaesth 1991;66:625626.

17. Woehlick HJ, Dunning M, Nithipatikom K, Kuller AH, Henry DW. Mass spectrometry provides warning of carbon monoxide exposure via trifluoromethane. Anesthesiology 1996;84:1489-1493.

18. Centers for Disease Control. Epidemiological notes and reports elevated intraoperative blood carboxyhemoglobin levels in surgical patientsGeorgia, Illinois, and North Carolina. MMWR 1991;40:248-249.

19. National Institute for Occupational Safety and Health. NIOSH Pocket Guide to Chemical Hazards. Atlanta, GA: US Department of Health and Human Services, Public Health Service, Centers for Disease Control and Prevention; 1994

\title{
Serratia Outbreak From Contaminated Pressure-Monitoring Equipment
}

\section{Gina Pugliese, RN, MS \\ Martin S. Favero, PhD}

Harnett and colleagues, from the United Kingdom, have reported on an outbreak of Serratia liquefaciens. Between October and December 1999, S liquefaciens was isolated from 11 patients in an adult critical-care unit. One patient was infected on two separate occasions. In total, there were 10 positive blood cultures and 5 positive intravascular catheter tips. Eight cases were clinically infected, 3 were possibly infected, and 1 was not. All patients with clinical isolates received appropriate empirical antibiotic treatment.

Environmental investigation revealed
S liquefaciens in syringes and connector tubing used to calibrate the intravascular-line pressure-monitoring equipment of eight patients. Three of these patients also had clinical isolates of $S$ liquefaciens. Analysis by pulsed-field gel electrophoresis found clinical and environmental isolates to be of the same strain. The most likely mode of transmission was a nonsterile sphygmomanometer tip used daily for calibration. Inadequate microbiological sampling methods may have limited detection of $S$ liquefaciens. Several other examples of poor infection control techniques were identified during the outbreak, notably lapses in hand hygiene during intravascular pressure monitoring. It also was observed that unlabelled multidose heparin and insulin vials were shared between patients, and personal hand creams were used by staff. However, these were not directly implicated in the outbreak. The outbreak ended when poor infection control practices were corrected. Calibration syringes and connector tubing were discarded after a single use. The sphygmomanometer was replaced by a pneumatic pressure transducer tester with connector tube and the frequency of calibration reduced to a single test following line insertion only. The nondisposable tube was disinfected with alcohol wipes between patients.

FROM: Harnett SJ, Allen KD Macmillan RR. Critical care unit outbreak of Serratia liquefaciens from contaminated pressure monitoring equipment. $J$ Hosp Infect 2001;47:301-307. 